\title{
Müzelerde Sergilenen Envanterlerin Propaganda Amaçlı Kullanımında Malta Şövalyeleri Müzesi Örneği
}

\author{
Aysun ALTUNÖZ ${ }^{1}$ ve Bülent SALDERAY ${ }^{2}$
}

$\ddot{O} z$

$\mathrm{Bu}$ araştırmada, müzelerde sergilenen envanterlerin propaganda amaçlı kullanımına yönelik Malta Şövalyeleri Müzesi bir örnek olarak ele alınmış ve konu çeşitli açıardan ele alınarak değerlendirilmiştir. Bu kapsam doğrultusunda; araştırmada, nitel araştırma yöntemleri içerisinde yer alan betimsel araştırma yöntemi kullanılmııstır. Araştırma kapsamında, Malta Şövalyeleri Yerel Tarih Müzesi içerisinde sergilenen öğeleri yansıtan eserlerin belirli bir fikri ve düşünceyi yansıttığına yönelik bulgulara ulaşılmıştır. Elde edilen bu bulgulardan hareketle; (1) tematik müze kapsamında değerlendirilen Malta Şövalyeleri Yerel Tarih Müzesi içinde sergilenen ve Malta'nın tarihsel sürecini anlatan balmumundan yapılmış üç boyutlu figürler ile görsel ve işitsel sunuların, bilinçaltına etki ettiğgi ve ziyaretçilerin algılarının yönlendirmesine neden olduğu; (2) Malta Şövalyeleri Yerel Tarih Müzesi içinde sergilenen ve Malta'nın tarihsel sürecini anlatan balmumundan yapılmış üç boyutlu figürler ile görsel ve işitsel sunuların, bakış açısına bağı olarak gizli propagandayı çağrıştıran öğeler içerdiğ̈; (3) Malta Şövalyeleri Yerel Tarih Müzesi’nde kullanılan envanterlerin, müzeyi ziyaret eden art niyetli ziyaretçiler tarafindan, konunun farklı şekilde ele alınıp değerlendirilmesi ve düşünce ve davranışlarının eyleme dönüşmesine firsat verdiği yönünde bir sonuca varılmıştır.

Anahtar Kelimeler: Müze, Propaganda, Envanter, Malta şövalyeleri, Sanat eseri

\section{Example of Maltese Knights Museum for Exhibiting Inventories in Museums that Using} As Propaganda

\section{Abstract}

In this research has been evaluated as an example of Maltese Knights Museum for exhibiting inventories in museums that using as propaganda from different perspectives. In this context; was used descriptive research method which is one of the qualitative research methods. In the scope of the research, it has been obtained these findings; exhibiting inventories in Maltese Knights Local History Museum reflects a particular idea and thought. Based on the findings it has been mention these results: (1) Visual and audio presentations with three-dimensional figures that were made of wax which describing the historical process of Malta and exhibiting in Maltese Knights Local History Museum affect the subconscious and cause to guide visitors' perceptions the perception manipulatively. (2) Visual and audio presentations with three-dimensional figures that were made of wax which describing the historical process of Malta and exhibiting in Maltese Knights Local History Museum contain elements that evoke secret propaganda depending on the perspective. (3) Using inventories in Maltese Knights Local History Museum gives opportunity to address and evaluate the subject differently and to turn their thoughts and behaviors into action by malicious visitors who visited the museum.

Key Words: Museum, Propaganda, Inventory, Knights of Malta, Artwork

\section{Atıf İçin / Please Cite As:}

Altunöz, A. ve Salderay, B. (2020). Müzelerde sergilenen envanterlerin propaganda amaçlı kullanımında Malta Şövalyeleri Müzesi örneği. Manas Sosyal Araştırmalar Dergisi, 9(3), 1598-1607.

Geliş Tarihi / Received Date: 16.03 .2020

Kabul Tarihi / Accepted Date: 22.04.2020

\footnotetext{
1 Doç. Dr. - Türkiye -Ankara Hacı Bayram Veli Üniversitesi Güzel Sanatlar Fakültesi, altunozaysun@gmail.com ORCID: 0000-0003-3857-3704

2 Prof. Dr. - Türkiye - Ankara Hacı Bayram Veli Üniversitesi Güzel Sanatlar Fakültesi, bsalderay@gmail.com ORCID: 0000-0002-8133-6192
} 


\section{Giriş}

Müzeler, bilimsel, kültürel, sanatsal, tarihsel olarak önem arz eden insan yapımı olan veya olmayan tüm nesneleri toplayan, bakım ve korumasını yapan yapılandırlmış enstitülerdir. Müzeler sahip oldukları koleksiyonu/koleksiyonlanı belirli bir süre sergileyebildikleri gibi; kalıcı olarak da ziyaretçilerin ziyaretine açabilmektedirler.

Müzeler; sanat, doğa tarihi, bilim, savaş, çocuk müzeleri, gibi birçok farklı türde sınıflandırılmıştır. Her ne türde ve çeşitte olursa olsun müzeler; yerelden evrensele ulaşma, geniş kitlelere ulaşma ve yayılma politikasını taşımaktadır. Bununla birlikte; bir ülkenin kendi kültürünü, tarihini, zenginliklerini, değerlerini, vb. yaşatabilmek, kendi gelecek nesillerine ve dünyadaki diğer nesillere aktarabilmek, aidiyet duygusunu oluşturabilmek, konu/tema ile ilgili ülke ve dünya genelinde farkındalık yaratabilmek, bilinç oluşturabilmek ve yaygınlaştırabilmek için etkili sunum stratejilerine, görsel etkilere ve eğitim yapılanmasına da ihtiyaç duymaktadır. Bu ihtiyaç ve gereksinim sürecinde ise eğitim olgusu önemli bir rol oynamaktadır (Ramachandran ve Hirstein, 1999; Hooper-Greenhill, 2007). Malta Şövalyeleri (The Knights of Malta) Yerel Tarih Müzesinde çocuklara yönelik verilen sesli ve görsel eğitimin içeriği de Malta'nin milli değerlerine hizmet eden bir yaklaşımı içermektedir.

Tematik müzeler ise; genelde belirli bir tema, konu veya bölgeyi yansitan koleksiyonlar veya mirasa dayalı öğelerin karșılaștırmalı incelemesini ele almaktadır. Bu doğrultuda; tematik müzeler, toplumların kendilerine özgü en önemli ve bölgesel olarak en ayrıt edici, kendine özgü, taşınabilir mirasını/miraslarını canlandıran, belgeleyen ve tanımlayan müzelerdir (Hooper-Greenhill, 2007; Hubard, 2014). Binlerce turistin ziyarette bulunduğu Malta Şövalyeleri Yerel Tarih Müzesi de Malta tarihi geçmişini ve değerlerini milli çıarlar doğrultusunda gözler önüne seren tematik bir müze olarak yer almaktadır.

Bunun yanı sıra benimsemiş olduğu milli politika ve propagandayı dünya geneline yaymak için her türde sanat alanını, görsel medya, işitsel medya, basılı medya, internet ve yeni medya, diğer iletişim araçlarını, vb. birçok unsuru bir arada kullanarak milli tarih ve kültürünü, gizli propaganda araçları kullanarak algıyı yönlendirdiği ve bu süreçte başka bir kültüre ait değerleri ve/veya ırka dayalı nitelikleri bilimsellik ve tarafsızlık ilkesine dikkat etmediği varsayılmaktadır. Devletlerin, ülkelerin milli çıkarlara dayalı olarak belirlemiş oldukları algı yönetimi politikası, özellikle turistik şehirlerde açılan tematik, tarihsel, vb. müzelerde kedini bire bir gösterdiği bilinir.

Bu doğrultuda; müzelerde sergilenen envanterlerin propaganda amaçlı kullanımında malta şövalyeleri müzesi örneği nasıldır? sorusu araştırmanın problem sorusu olarak belirlenmiş ve müzede yer alan tematik görsellerin propagandaya dayalı bir yapıyı yansıtıp yansıtmadığı ve bir kültüre ırka yönelik herhangi bir alg1 yönetiminin kullanılıp kullanılmadığı ele alınarak değerlendirilmiştir.

\section{Yöntem}

Makalenin genelinde nitel araştırma yöntemlerinden destekle verilerin analizinde betimsel (durum saptayıc1) araştırma modeli kullanılmıştır. Tematik müzeler evreninde yer alan Malta Şövalyeleri Tematik Müzesi kapsaminda sergilenen, herhangi bir kültüre yönelik alg1 yönetimine hizmet ettiği varsayılan ve propaganda içeriğine sahip olabilme olasıllı̆g üzerinde durulan üç boyutlu müze envanterleri ile sınırlandırılmıştır. Bu envanterler müze genelinden problem durumuna yönelik rastgele seçilen figürlerden oluşmaktadır. Figürlerin betimlemeleri bu problem doğrultusunda ele alınmış ve içerik analizleri yapılmıştır. Karşılaştırmalı yapılan bu analizlerde figürlerin ifadeleri ve izleyicide bıraktığı duygu ve oluşturduğu alg1 üzerinde durulmuştur.

\section{Bulgular}

Malta Tarihinde Şövalyelerin Yeri: Deniz ticaretinde Akdeniz'in ortasında önemli jeopolitik konuma sahip olan Malta'nın siyasi tarihinde şövalyelerin adı birinci Haçlı Seferlerine dek uzanmaktadır. Kırval (2013, s. 40), Malta Şövalyelerini (Tapınak Şövalyeleri, Hospitalye ya da St. John Şövalyeleri³) Katolik dünyasının Osmanlı İmparatorluğu'na karşı oluşturduğu bir kuvvet olarak tanımlamaktadır'. Yüzyıl

\footnotetext{
3 Haçlı seferleri sırasında Hastane Rahipleri (Hospitallers) ve 1530'dan sonra ise Malta Şövalyeleri olarak bilinen St. John Şövalyeleri'nin, 1530'da adaları kontrolü altına alması, Malta tarihinde bir dönüm noktası olmuştur (Castillo 51). O döneme kadar Malta'nın tarihi Sicilya'nınkine bağlı iken Şövalyeler döneminden itibaren bağımsız bir yol izlemiştir. (Kurtulmuş, 2018, s. 1844)

4 St. John Şövalyeleri 1100 yılında kurulmuş olup, uzun yıllar Haçlı ordularını korumuş ve kutsal topraklara giden Haçlı güçlerine sürekli yardımcı olmuşlardır. Müslümanlar 1187'de Kudüs’ü fethettiğinde ise St. John Şövalyeleri Akdeniz’e açllp kendilerine yeni
} 
boyunca yenilgiye uğramamış Osmanlı İmparatorluğu donanmasının yenilmezliği, 20. yüzyıla kadar sömürge devleti olan Akdeniz'in ortasında ticari ve askeri stratejik üne sahip Malta'nın kuşatması sırasında sekteye uğramıştır. Ortaya çıkan bu durum, sonraları "Malta" ve özellikle "Malta Şövalyeleri”" için önemli bir dönemi işaret etmektedir.

St. John Şövalyeleri olarak da bilinen Malta Şövalyelerinin, 1100 yllında kurulan bir birlikle tarih sahnesinde yer aldıkları görülmektedir. Kutsal toprakları ziyaretleri sırasında rahatsızlanan hacıların öncelikle Kudüs'te ve sonrasında da Malta'da kurulacak hastanelerde bakımlanı ve tedavilerini üstlenen, bu kuruluşun finanse ve organizasyonundan sorumlu şövalyeler (hospitaler) manastır emri (manastıra bağlı fedailer) olarak anılmaktadırlar. Adalar grubu içerisinde yer alan Malta, tarihinde birçok istilaya maruz kalmıştır. Korku saçan berberi (barbary) korsanları ile mücadele eden ve Papaya bağlllıkları ile bilinen Malta şövalyelerinin Müslüman egemen güce karşı Kudüs'teki kutsal toprakların korunmasında önemli misyona sahip olan askeri düzen (Tapınak Şövalyeleri) olarak da bilinmektedirler. Katolik inancına göre; bu şövalyeler savaşta öldüklerinde cennete gitme ayrıcalı̆̆ına sahip ve yeminlerinden dönmeyen korkusuz askerlerden oluşmaktadır. Tarih sürecinde Osmanlı İmparatorluğuna karşı önemli bir zafer kazanan şövalyeler hem dini, hem siyasi otoriteler tarafından destek görmüş ve yetki alanlarını genişletmişlerdir.

O dönemin Malta anayasasına göre Malta düzeni üç sınıfa ayrllmaktaydı. Her hangi bir sınıfa üye olanlar yaşamlarını katolik kilisesinin öğreti ve kurallarına göre biçimlendirmekteydiler. Birinci sınıf: mesleki konvansiyonel papazlardan, ikinci sınıf: ilkeler doğrultusunda hareket etmeye yeminli şövalyelerden ve üçüncü sınıf ise: yeminli olmayan ancak kilise ve düzen ilkelerine göre yaşayan meslek dışı üyelerden oluşmaktaydi. (https://theknightsofmalta.com/history/\#_tkosj), (29.02.2020).

Malta şövalyelerinin Malta'da yaşayan yerel halk ile sosyal ve kültürel bağlamda bir birlikteliği olmadığ1 bilinmektedir. Osmanlı İmparatorluğu Padişahlarından Sultan Süleyman'ın Rodos'u fethinden sonra buradaki Şövalyelerin (St. John Şövalyelerinin) Maltaya sığındıkları yazılı kaynaklarda belirtilmektedir. Malta tarihinde, Fenikeliler ile akrabalık ilişkileri içinde oldukları ifade edilmektedir. Günümüzde Maltaca olarak bilinen dil Arapçaya oldukça yakın bir dildir. Ayrıca; Malta mimari yapının yanı sıra; coğrafi koşullardan da kaynaklı Fas, Cezayir, Tunus vb. yapı kültürü ile benzerlik göstermektedir. Yüzyıllarca sömürü altında kalan Malta'nın yalın bir halk kitlesine sahip olduğu söylenemez. Öyle ki günümüzde Malta Cumhuriyetinin Anayasası'nın 32. Maddesinde bireyler arasında herhangi bir ayrım yapılmamasına ilişkin aşağıdaki kesin hüküm yer almaktadır.

"Her birey temel hake ve özgürlüklere sabiptir. Bir baska ifade ile bu baklar (yasam, özgürlük, kişi güvenliğ̈, mülkiyet hakker, bukukun korunmasi, vicdan, ifade, toplant yapma, dernek kurma özgürlïgü, özel hayata ve aile bayatina saygi) rrk, köken, siyasi görïs, renk, mezhep ve cinsiyet gözretilmeksizin sahip olunan ve saygr duyulması gereken haklardir, (Günes, 2017, s. 318).

Günümüz Malta Cumhuriyeti'nde her ne kadar yasalar kesin zorunlulukları emretse de, göz ardı edilen ve önemsiz gibi görünen bazı durumlar, yapılanmalar; Malta'nın tarihini merak eden veya Malta'yı turist olarak ziyarette bulunan ziyaretçiler üzerinde geri dönüşü olmayan bir takım ön yargıya dayalı çıkarımsamalara varılmasına zemin hazırlayabilmektedir.

Bu belirtilenler 1şığında; Malta adasında yer alan tematik müzeler kapsamında nitelendirilen "Malta Şövalyeleri Müzesi” araştırma kapsamında ele alınmıştır. Bu doğrultuda; müze içerisinde sergilenen envanterler ve fiziki durumun, ziyaretçilere yönelik bir alg1 yönlendirmesini içerip içermediğinin değerlendirilmesi de hedeflenmiştir.

Tematik Müze Örneği: Malta Şövalyeleri Yerel Tarih Müzesi (The Knights of Malta): Mdina'da bulunan Malta Şövalyeleri Tematik Müzesi Malta tarihinin en hareketli dönemlerini üç boyutlu görseller, video ve sesli rehberlik hizmetinin yanı sıra; müze planı, görme engelli ziyaretçilerin rehber köpekleri eşliğinde tanıklık etmelerine olanak sunmaktadır. Birçok farklı bölümden oluşan müze, ş̧ıklı patikalarla ve sesli anlatımlarla çeşitlendirilmiştir. Tekli ya da grup ziyaretlerine olanak tanıyan müzede alegorik bir anlatım tercih edilmiş olmakla beraber; çocuklara yönelik eğitim programları da içermektedir (Resim 1).

üsler aramak zorunda kalmışlardır. Bu çerçevede, önce Kıbrıs'a yerleşmişler, daha sonra Rodos'a geçmişler; Rodos'un Osmanlılarca fethinden sonra da önce Sicilya'ya çekilen Şövalyeler, Malta adasının İspanyol kralınca kendilerine verilmesi ile son olarak Malta'ya çok güçlü bir şekilde yerleşmişlerdir. Çoğunlukla Avrupa'nın nitelikli ailelerinden gelen ve Hz. İsa adına ölmeye hazır olan Şövalyeler, esas itibariyle Katolik dünyanın (özellikle de Vatikan'ın) Doğu Akdeniz'de Osmanlılara karşı en önemli uc beyliğini oluşturmuşlardır. St. John Şövalyeleri’nin o yıllarda sürekli olarak Osmanlı ticaret gemilerine saldırması nedeniyle Malta adasının alınması Osmanlı'nın Akdeniz ticaret güvenliği acısından kilit önem arz etmeye başlamıştır (Kırval, 2013, s. 40) 


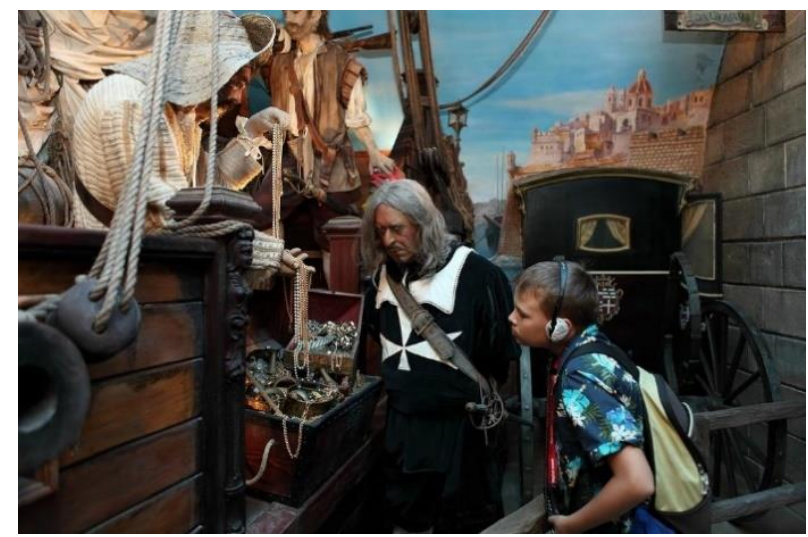

Resim 1. Malta Ş̈valyeleri Yerel Tarih Müzesi, Mdina, Malta

Bilindiği üzere Müze Eğitimi (Müzede Eğitim); müzeler gibi enstitüler ve resmi olmayan eğitim alanlarının eğitim rolünü güçlendirmek ve geliştirmek için yapılandırılmış özel alanlarda gerçekleştirilen bir eğitim sürecidir. Temel olarak müze eğitimi süreci, müzede var olan nesneler, koleksiyonlarla bağlantılı bir şekilde ziyaretçilerin meraklarını artırarak ve ilgilerini çekerek öğrenme deneyimlerinin artırmasını hedeflemektedir. Coombs, Prosser ve Ahmed (1973) 'Kırsal Bölge Çocukları ve Gençlerin Öğrenmeleri için Yeni Patikalar" bașlıklı çalıșmada; ülkenin dört bir yanındaki çocuk ve gençlere ulaşmak, ülkenin mevcut genel milli eğitim yapısına destek olmak, kendi ülke çıkarlarını gözeten ve bunu yaşatan nesilleri yetiştirmek, milli eğitim yapısındaki mevcut öğretileri ve ilkeleri daha etkili ve bilginin kalıcllğını sağlayacak şekilde aktarmak, ülke çıkarlarını gözeten ve bu ideolojiyi yaşatan bireyler yetiştirmek için tüm ülke genelindeki müzelerin resmi olmayan eğitim alanları içerisinde değerlendirilmesinin gerekliliğine ve bu doğrultuda tematik müzelerin oluşturulmasına yönelik ihtiyaca vurgu yapmaktadırlar. Bu doğrultuda oluşturulan temaya dayalı müzeler; ele aldıkları temayı daha etkili sunmak ve kalıcılığı sağlamak için bütün duyu organlarına hitap edecek, görsel anlamda etkili, etkileşimli düzeneklerle fiziki yapılarını güçlendirmekte ve/veya bu düşünceye dayalı olarak yapılanma stratejileri geliştirmektedirler (American Association of Museum, 2000; Hooper-Greenhill, 2007; Bell, vd. 2009; Hager ve Halliday, 2009; Hubard, 2014).

Malta Şövalyeleri Yerel Tarih Müzesi bu bağlamda çocukların dikkatini konuya çekmek, bilginin (vurgu yapılan milli değerlerin) kalıcılığını artırmak ve öğrenmeyi kolaylaştırmak amacıyla önemli bir araç olarak kullanılmıştır. Bu noktada kullanılan figürlerin hareketleri, ifadeleri, giysi ve aksesuarları ile iç mekan aydınlatmaları en az sesli anlatımların içeriği kadar özenle seçilmiştir. İzleyici karanlık küçük bir mekanda ansızın karşısına çıkan sahnenin içinde bulur kendisini, adeta olayın tanığıdır. Bilinçli kurgulanan bu mekanlar izleyicide aidiyet duygusunu pekiştirmektedir. Böylece yaşayarak öğrenme ve öğrenileni pekiştirmekle bilginin kalıcllı̆̆ desteklenmektedir (Resim 2).

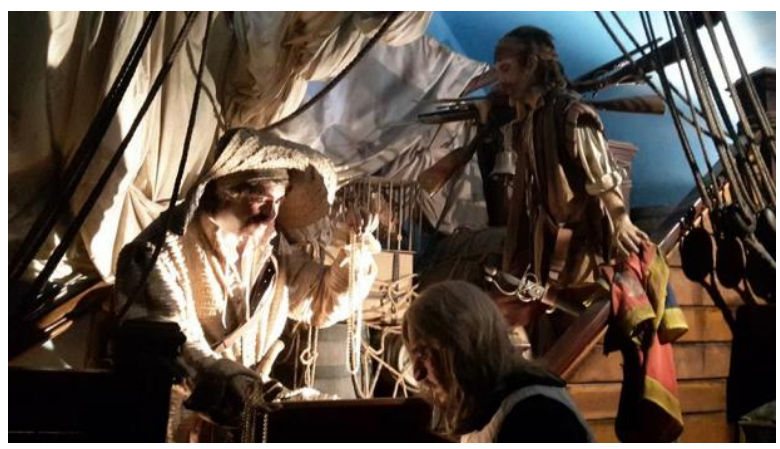

Resim 2. Malta Şövalyeleri Yerel Tarih Müzesi, Mdina, yazar arşivi, 28-0cak- 2016, Malta

Genel olarak müze konsepti; Tapınak Şövalyeleri, Hospitalye ve St. John Şövalyelerinin tarihte anıldıkları başarıları içermektedir. Müzede yer alan her bir bölüm (seksiyon) şehrin Osmanlı İmparatorluğu tarafindan ele geçirilme sürecini, buna karşın Malta şövalyelerinin mücadeleleri ile şehrin yeniden inşa 
süreci ve benzer tarihi önem içeren konuları, üç boyutlu figürlerle, övgü dolu sahneler eşliğinde, teatral bir dille anlatmaktadır. Karanlık iç mekandaki sesli ve 1şıklı yönlendirmeler, tarihsel hikayelerin görselleri eşliğinde, bölümleri (seksiyonların) kronolojik takibini kolaylaştırmaktadır. Kulaklıktan gelen komutlar ve ansızın yanan 1şık huzmesiyle yönlendirilen ziyaretçiler, dinlediği metnin etkisinden kurtulmadan görsel bir uyarıcı ile karşılaşmaktadır. Görünen sahne ile beraber izleyicinin hafızasında güçlü bir alg1 oluşturulmaktadır. Kayıt cihazından kulaklıklar aracilığı ile verilen sesli canlandırmalar, 1şıklı yönlendirmeler, her bir bölümde (seksiyonda) farklı tarihi olayı anlatan balmumundan yapılmış figürlü sahneler ile figürlerin ele alınış biçimleri, yaratılmak istenen algiyı ve psikolojik etkiyi pekiştirmektedir (Resim 3).

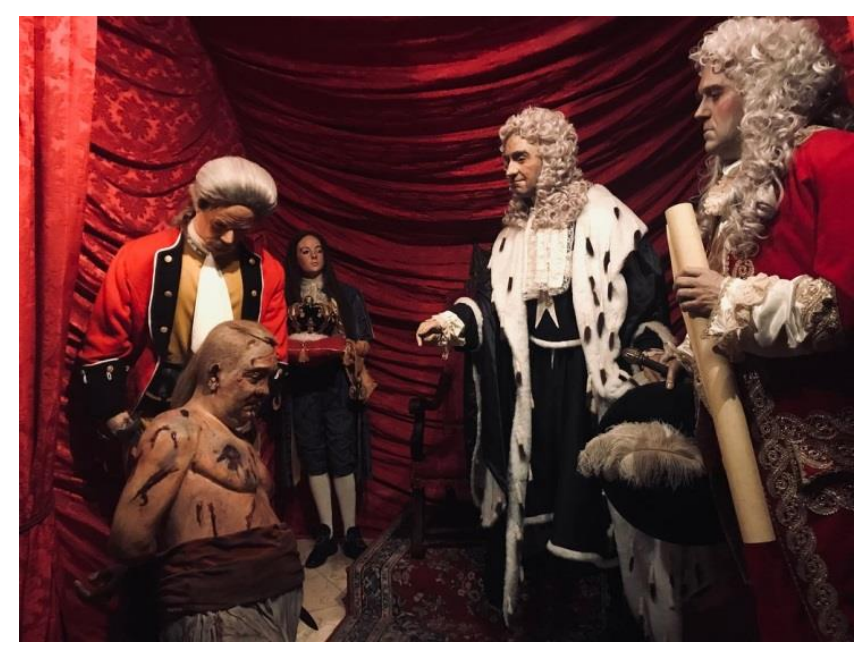

Resim 3. Malta Şövalyeleri Yerel Tarih Müzesi, Mdina, Malta

Dünya üzerinde gelişmiş olarak nitelendirilen uygarlıkların kurulmasından bu yana; iktidarlar; kısacası yapının veya yapıların yönetiminde rol oynayan kişiler, toplumu yönetebilmek, aidiyet duygusunu oluşturabilmek, kişilerin fedakârlıkta bulunmalarını sağlamak, istenilen davranış ve düşünce yapısını kazandırmak için alg1 psikolojisini kullanmışlardır. 20. yüzyllla birlikte küreselleşen dünya yapısı, alg1 psikolojisinin kullanımını artırmıştır. Algı psikolojisi, genelde sadece iktidarlar tarafindan yoğun olarak kullanılırken, 20. yüzyılla birlikte, basın yayın kuruluşları, firmalar, şirketler vb. daha küçük düzeydeki yönetimsel yapılar tarafindan da kullanılmaya başlanmış ve kullanım alanı yaygınlaştırılmışır (Bowart, 1978; Gordon, 2005; Hager ve Halliday, 2009; Salderay, 2016).

Resim 3'de yer alan kompozisyonda savaş esiri olduğu vücudundaki kan izlerinden, diğer figürlere göre aldığ konumdan ve yüzündeki ifadeden belli olan figürün ve kompozisyonun izleyici üzerinde nasıl bir etki bıraktığı, bu bağlamda değerlendirilmesi gereken önemli bir örnektir. Figürler arasındaki sınıfsal fark alegorik bir dille açıkça sergilenmektedir. Genel anlamda 'esir' savaşta ele geçirilen kişi ile tanımlanır. Kelimenin etimolojik anlam ve içeriği ile eş anlamlı olan 'tutsak' kelimesi ve 'tutsak düşmek' 'tutsak edilmek' deyimi arasında algısal bağlamda fark olduğu varsayılırsa, Resim 3'de esir alınanın bir düşman olduğu ve bu muameleyi hak ettiği alg1sı yaratılmaktadır. Bu alg1 ayaktaki figürlerin mimikleri, kiyafetleri, arka fonda kullanılan kumaşın, halının rengi ve figürün elinde tuttuğu kağıt rulosu ile esirin arkadan bağlanmış elleri ve yüzündeki yenilmişlik ve kabullenmiştik göstergeleri ile pekiştirilmiştir. Dizleri üzerine çökmüş biçimde konumlandırılmış esir özelde Osmanlı'nın ya da Barbarilerin yenilgisini simgelemektedir. Bilindiği gibi Malta şövalyelerinin tarihte en çok korktukları bu iki askeri güçtür. 


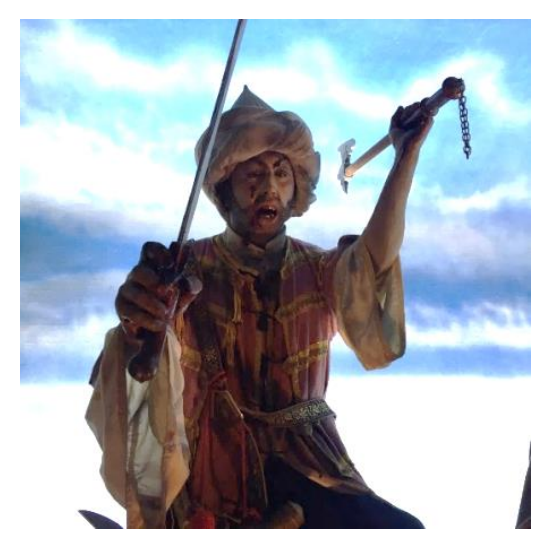

Resim 4. Malta Şövalyeleri Yerel Tarih Müzesi, Mdina, Malta

Genel bilinene göre figüratif heykelde anlatım-ifade, sanatçının içinde bulunduğu duygu durumunu açığa çıkarmaktadır. Belli bir duygu ya da olgunun betimlenmesi sanatçı ve konu arasında kurulan empatinin gücü ile doğru orantılıdır. Bu ilişki ne kadar güçlü kurulur ise mesaj izleyiciye o derce net iletilmiş olur. Bu değerlendirmeler ışı̆ı̆ında Resim 4-5-6'da ayrıntıları verilmiş savaş sahnelerinde yer alan karakterler arasındaki betimsel çözümlemeler duygusal bağlamda ortaya konan farkı açıkça göstermektedir. Kullanılan aksesuarlar ile pekiştirilen yüzlerdeki ifadeler zalimle mazlumun, soylu ile barbarın sınırlarını sert bir anlatım dili ile belirlemektedir. Bu göstergeler izleyiciyi, konunun içeriğinde yer alan gruplar arasında, taraf olmaya teşvik etmektedir. Resim 4'te betimlenen karakterin çözümlemesi yüzündeki ifade ve elindeki aksesuarlardan destekle barbar, acımasız ve istilac1 olarak şekillenmektedir tıpk1 Resim 5'te görüldüğ̈ gibi. Tek fark kıyafetlerdir. Her iki örnekte de ortak özellik istilacı olmalarıdır.

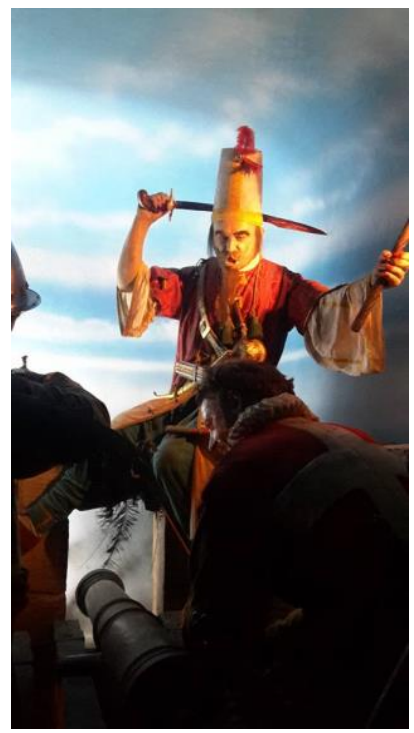

Resim 5. Malta Şövalyeleri Yerel Tarih Müzesi, Mdina, yazarar arşivi, 28-0cak- 2016, Malta

Resim 5 ve 6'da yer alan örnek görseller diğer iki görsele tezattır adeta. Giysilerinin muntazamlığı, mimikler ve konumları savunmada yer alan şövalyeleri işaret etmektedir. Milli propagandaya açıça hizmet eden bu betimleme şekli müzelerin amaç ve işlevleriyle çelişmektedir. Genelde tematik müzeler, kendi bulundukları bölgesel yapının özellikleri, değerleri, stratejik, coğrafik ve ekonomik konumu, ülke ve dünya politikası, milli görüş ve oluşturulan milli propaganda misyonuna bağlı olarak, yazılı ve görsel koleksiyonunu, fiziki öğelere yönelik düzenlemelerini ve yazılı, görsel, işitsel tanıtım, reklamlarını şekillendirebilmektedirler. Bununla birlikte; özellikle ülkenin benimsediği milli politika ve propaganda yapıs1, müze ziyaretçileri üzerinde oluşturulmak istenen algının şekillenmesinde de rol oynayabilmektedir (Falk ve Dierking, 1992; Hubard, 2014). Ancak bu durum hassasiyetle değerlendirilmelidir. 


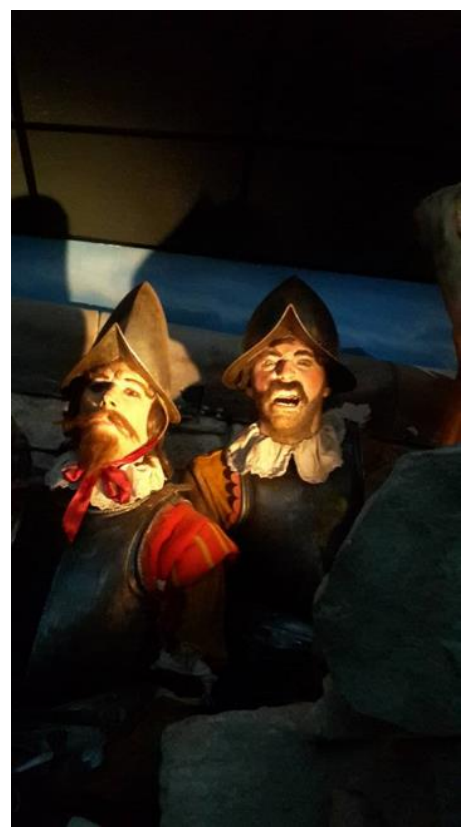

Resim 6. Malta Şövalyeleri Yerel Tarih Müresi, Mdina, yą̧ar arşivi, 28-Ocak- 2016, Malta

Malta Şövalyelerinin kısa tarihinden söz eden müzenin resmi sayfasında; şu şekilde önemli bir anekdot yer almaktadir:

Savaşın en hararetli noktasında, Osmanhlar, ele geçirilen Ş̈̈valyelerin başsız cesetlerini Büyük Liman'da denize attılar. Buna cevaben, Vallette de, tüm Osmanli mabkumlarnin infaz. edilmesini emretti ve St Elmo'daki Osmanl vatandaşlarına ateş etmek için bu mabkumlarn kesike başlarm 'top güllesi' olarak kulland. (https:/ / theknightsofmalta.com/ history/\#_tkosj), (29.02.2020).

Savaşın vahşeti yadsınamaz bir gerçektir. Ancak toplumun her kesiminin kullanımına açık, interaktif dünyada ulaşılabilirliği olan müze gibi önemli kuruluşlarda bu tür paylaşımların özenli seçilmesi gerekmektedir. Müzelerde ziyaretçilere sunulan sesli, yazılı ve görsel sunumların yoruma dayalı, taraf olmadan, doğrudan bilimsel aktarımlarla yapılmasının bilgi kirliliğini önleyeceği gibi müzelere yüklenen eğitim, öğretim görevlerini de bilimsel düzeyde etik değerler çerçevesinde yerine getireceği bir gerçektir.
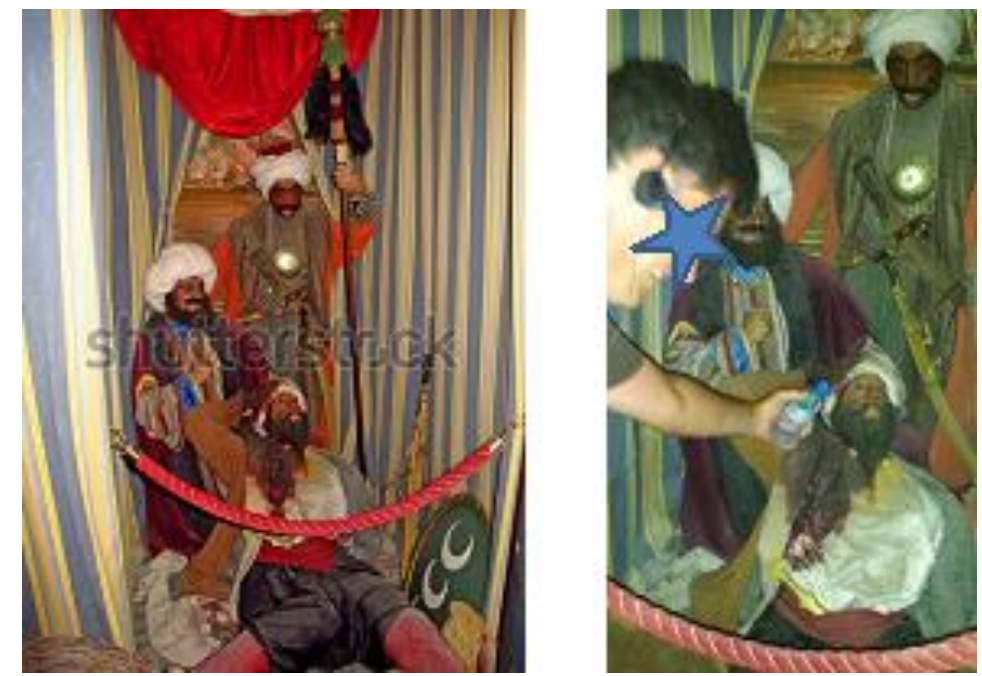

Resim 7. Malta Şövalyeleri Yerel Tarih Müzesi, Mdina, Malta

Müzelerin milli propaganda ve eğitim misyonları göz önünde bulundurulduğunda, sergilenen objeler ile canlandırmaların din, dil, 1rk, cinsiyet, vb, konular arası ayrıma vurgu yapmadan, milli değerleri ön plana çıkarırken doğabilecek sorunlara uzmanlar ve organizatörler tarafindan hassasiyetle önlem alınması kaçınılmaz bir gerekliliktir. Öyle ki müzelerde temanın amacının dışında ziyaretçileri yanlış davranışlara 
yönlendirecek, tarafll-yanlı bilgilendirme yapacak sergiler, betimlemeler ve yorumlardan kaçınılmalıdır. Duyumlar aracilığyla Resim 7'te yer alan olgular-konular anlamlandırıldığında bir alg1 oluşturulma çabasının olasılığı akla gelebilmektedir. Kompozisyon içinde yer alan göstergeler; figürlerin yüzlerindeki ifadeler, kullanılan nesneler, semboller ve içerik-tema izleyiciyi açık uçlu yorumlara, algıllara yönlendirmektedir. Savaşın vahşeti anımsatan sahneleri tarihte olagelmiştir. Ancak; ziyaretçi çeşitliliği olan müzelerde bu tür göstergelerin, anlatıların kullanılması hususu dikkatle sorgulanmalıdır.

\section{Tartışma, Sonuç ve Öneriler}

Tematik müze kapsamında değerlendirilen Malta Şövalyeleri Yerel Tarih Müzesi içinde sergilenen ve Malta'nın tarihsel sürecini anlatan balmumundan yapılmış üç boyutlu figürler ile görsel ve işitsel sunuların, bilinçaltına etki ettiği ve ziyaretçilerin algılarının yönlendirmesine neden olduğu sonucuna varılmıştır. Malta Şövalyeleri Yerel Tarih Müzesi içinde sergilenen ve Malta'nın tarihsel sürecini anlatan balmumundan yapılmış üç boyutlu figürler ile görsel ve işitsel sunuların, bakış açısına bağlı olarak gizli propagandayı çağrıştıran öğeler içerdiği sonucuna ulaşılmıştır. Malta Şövalyeleri Yerel Tarih Müzesi'nde kullanılan envanterlerin, müzeyi ziyaret eden art niyetli ziyaretçiler tarafindan, konunun farklı şekilde ele alınıp değerlendirilmesi ve düşünce ve davranışlarının eyleme dönüşmesine firsat verdiği yönünde bir sonuca varılmıştır. Bu noktada alınması gereken önlemler uygulamalara ve araştırmalara yönelik olarak iki başlık altında toplanmıştır:

Uygulamaya yönelik; yoruma ve farklı okumalara açı her türlü göstergenin, toplumun hizmetine sunulduğu mekanlarda ve özellikle eğitim misyonu olan müzelerde, özenle ve bilimsel kriterlere uygun olarak kullanılması önerilmektedir. Tematik müzelerde sunulan öğelerin ırksal, dinsel, kültürel, vb. yapılar açısından ayrımcılığı tetiklemeyecek şekilde tarafsız bir gözle sunulması önerilmektedir.

Diğer taraftan Müzelerin eğitsel boyutu dikkate alındığında, çocuk, ergen, yaşlı, hasta, engelli, vb. bireylerin anlamlandırma sürecini bozacak göstergelerin; bu bireylerin ziyareti esnasında travmatik sonuçlar oluşturabileceği gerçeğinin göz önünde bulundurulması önerilmektedir. Bu bağlamda da Malta Mdina’da yer alan Malta şövalyeleri Yerel Tarih Müzesi’nin propaganda içerikli yönlendirmelerden arındırılarak; bilimsel ve etik değerlere dikkat edilerek, sunuşunun yeniden ele alınması önerilmektedir.

İleri araştrrmalara yönelik öneriler çerçevesinde; Malta Şövalyeleri Yerel Tarih Müzesi içinde sergilenen ve Malta'nın tarihsel sürecini anlatan balmumundan yapılmış üç boyutlu figürler ile görsel ve işitsel sunuların Türk ziyaretçiler üzerindeki etkisinin araştırılması önerilir. Bir başka araştırmada, Malta Şövalyeleri Yerel Tarih Müzesi içinde sergilenen ve Malta'nın tarihsel sürecini anlatan balmumundan yapılmış üç boyutlu figürler ile görsel ve işitsel sunuların Türk çocuk ziyaretçiler üzerindeki etkisinin araştırılması önerilmektedir.

Farklı bir açıdan, Malta Şövalyeleri Yerel Tarih Müzesi içinde sergilenen ve Malta'nın tarihsel sürecini anlatan balmumundan yapılmış üç boyutlu figürler ile görsel ve işitsel sunuların özel gereksinimli ziyaretçiler üzerindeki etkisinin araştırılması önerilir.

\section{Etik Beyan}

"Mürelerde Sergilenen Envanterlerin Propaganda Amaçl Kullanmmnda Malta Şövalyeleri Müresi Örneğ̈" başlıklı çalışmanın yazım sürecinde bilimsel, etik ve alınt kurallarına uyulmuş; toplanan veriler üzerinde herhangi bir tahrifat yapılmamış ve bu çalışma herhangi başka bir akademik yayın ortamına değerlendirme için gönderilmemiştir.

\section{Kaynakça}

Bell, p., Lewenstein, B., Shouse, A. W. ve Feder, M. A. (2009). Learning science in informal environments. Washington, DC: National Research Council.

Bowart, W. (1978). Operation mind control; A magnificent book... moral, significant and unforgettable. UK: William Collins Sons \& Co. Ltd.

Coombs, P. H., Prosser, R. C. ve Ahmed, M. (1973). New paths to learning: for rural children and youth. International Council for Educational Development (ICED), Essex, Connecticut.

Güneş A. G. (2017). Malta'da din ve devlet ilişkileri. Süleyman Demirel Üniversitesi Sosyal Bilimler Enstitiusü Dergisi, 3(28), 313-324.

Haraway, D. (1989). Primate visions: Gender, race and nature in the world of modern science. New York: Routledge.

Hubard, O. (2014). Concepts as context: Thematic museum education and its influence on meaning making. The International Journal Art and Design Education, 33(1) 103-115. 
Falk, J. H. ve Dierking, L. D. (1992). The museum experience. Washington DC: Whalesback Books.

Gordon, I. E. (2005). Theories of visual perception (Third Edition). USA: Psychology Press, Taylor \& Francis Group.

Hager, P. ve Halliday, J. (2009). Recovering informal learning. Wisdom, judgment and community. Dordrecht: Springer.

Hooper-Greenhill, E. (2007). Museums and education. Purpose, pedagogy, performance. London. Routledge,

Kırval, L. (2013). Osmanlı imparatorluğu'nun 1565 Malta Kuşatması ve 16. yüzyıl'da Kanuni Sultan Süleyman'ın Akdeniz stratejisi. Journal of ETA Maritime Science, 1(2) 39-46.

Kurtulmuş Y. G. (2018). Malta dili üzerine tarihsel bir bakış. DTCF Dergisi, 58(2) 1837-1861.

Ramachandran, V. S. ve Hirstein, W. (1999). The science of art: A neurological theory of aesthetic experience. Journal of Consciousness Studies, 6(6-7), 15-51.

Salderay, B. (2016). Alg1 psikolojisi ve görsel sanatlar. Hitit Üniversitesi Uluslararası Geçmişten Geleceğe Sanat Sempozyumu. 26-28 Eylül, Kuzey Kampüsü, Çorum-TÜRKIYYE.

Malta Şövalyeleri Yerel Tarih Müzesi (2020). https://www.tripadvisor.com.tr/Attraction_Review-g190324d1751478-Reviews-or5-The Knights of Malta-

Mdina Island of Malta.html\#photos;aggregationId=101\&albumid=101\&filter=7 adresinden 05 Mart 2020'de alınmıştır.

Malta Şövalyeleri Yerel Tarih Müzesi (2020). (https://theknightsofmalta.com/history/\# tkosi), adresinden 29 Şubat 2020 tarihinde alınmıştır.

Resim1: https://www.tripadvisor.com.tr/Attraction Review-g190324-d1751478-Reviews-or5-

The Knights of Malta-

Mdina Island of Malta.html\#photos;aggregationId=101\&albumid=101\&filter=7\&ff=108730815), adresinden 29 Mart 2020'de alınmıștır.

Resim 2: Malta Şövalyeleri Yerel Tarih Müzesi, Mdina, yaz̧ar arşivi, 28-Ocak-2016, Malta

Resim3: https://www.tripadvisor.com.tr/Attraction_Review-g190324-d1751478-Reviews-or5-

The_Knights_of_Malta-

Mdina_Island_of_Malta.html\#photos;aggregationId=101\&albumid=101\&filter=7\&ff=108730815), adresinden 05 Mart 2020'de alınmıstır

Resim4: https://www.tripadvisor.com.tr/Attraction Review-g190324-d1751478-Reviews-or5-

The Knights of Malta-

Mdina Island of Malta.html\#photos;aggregationId=101\&albumid=101\&filter $=7 \& \mathrm{ff}=103838446$, adresinden 05 Mart 2020'de alınmıştır.

Resim 5. Malta Sövalyeleri Yerel Tarih Müzesi, Mdina, yazar arșivi, 28-Ocak-2016, Malta

Resim6:https://www.tripadvisor.com.tr/Attraction Review-g190324-d1751478-Reviews-or5The Knights of Malta-

Mdina Island of Malta.html\#photos;aggregationId=101\&albumid=101\&filter=7\&ff=103838446, adresinden 05 Mart 2020'de alınmıştır.

Resim7:https://www.tripadvisor.com.tr/Attraction_Review-g190324-d1751478-Reviews-or5-

The_Knights_of_Malta-

Mdina_Island_of_Malta.html\#photos;aggregationId=101\&albumid=101\&filter=7\&ff=103838446adresinden

29 Mart 2020’de alınmıştır.

\section{EXTENDED ABSTRACT}

Museums are structured institutes that collect, protect, conserve and restore all objects that are scientific, cultural, artistic, historically important, man-made or not. As museums can exhibit their collection/collections for a certain period of time; they can permanently open to visitors. However; Thousands of museums around the world are located in small cities, towns and rural areas, while the largest museums are located in large cities in many parts of the world. Museums can be in many different types, such as; art museums, natural history museums, science museums, war museums, children's museums, etc.

Museum Education (Education in Museum); It is an educational process in institutes such as museums and informal private areas that structure to strength and improve the inter-active role of education. Basically, the museum education process aims to increase the learning experiences by increasing the curiosity and interest of the visitors in connection with the objects and collections in the museum. As a result of the reconsideration of educational structures and programs after the II. World War, the role and importance of museum education is increasingly understood to create qualified societies. At this point, the importance and necessity of thematic museums are increasingly understood by the system creators.

However, the global structure of the world with the 20th century has increased the use of perception psychology. The perception management policy of the states based on national interests is very important. 
So the perception management, especially thematic, historical, etc., opened in tourist cities where human density and circulation are experienced, clearly visible in museums.

It is seen that the Republic of Malta has skill-fully raised and exposed its culture and values with the Museum of the Knights of Malta, which is visited by thousands of tourists. However; It appears to use many elements in order to spread the national policy and propaganda adopted by the Republic of Malta to all over the world, all kinds of art fields, visual media, audio media, print media, internet and new media, other communication tools, etc.. it can also be seen that the Republic of Malta has glorified its history and culture using perception management, which can be regarded as secret propaganda. It can be seen that the Republic of Malta, while promoting its own history and culture, presents its values and/or race-based qualities belonging to another culture to the visitors with a secret propaganda regardless of the principle of scientificity and impartiality and uses perception management skill-fully.

So in this research has been evaluated as an example of Maltese Knights Museum for exhibiting inventories in museums that using as propaganda from different perspectives. It was evaluated by considering whether the thematic images in the museum reflect propaganda and whether any perception management towards a culture is used.

In this context; was used descriptive research method which is one of the qualitative research methods. Descriptive research aims to explain the phenomenon and the situation in detail in terms of the general structure and basically "What happened?" and it was designed to answer "What's happening" questions. More specifically, descriptive research describes the current situation by searching it.

In the scope of the research, it has been obtained these findings; exhibiting inventories in Maltese Knights Local History Museum reflects a particular idea and thought. Based on the findings it has been mention these results: (1) Visual and audio presentations with three-dimensional figures that were made of wax which describing the historical process of Malta and exhibiting in Maltese Knights Local History Museum affect the subconscious and cause to guide visitors' perceptions the perception manipulatively. (2) Visual and audio presentations with three-dimensional figures that were made of wax which describing the historical process of Malta and exhibiting in Maltese Knights Local History Museum contain elements that evoke secret propaganda depending on the perspective. (3) Using inventories in Maltese Knights Local History Museum gives opportunity to address and evaluate the subject differently and to turn their thoughts and behaviours into action by malicious visitors who visited the museum.

At the end of the research about the results of the research, some suggestions were made for the application and for the advanced researches. Application Recommendations: (1) It can be suggested to use all kinds of indicators open to interpretation and different readings carefully and in accordance with scientific criteria in places where it is presented to the service of the society and especially in museums with educational mission. (2) Racial, religious, cultural, etc. of the items presented in thematic museums. it can be proposed to be presented with a neutral eye, without triggering discrimination in terms of structures. (3) Considering the educational dimension of museums, children, adolescents, elderly, sick, disabled, etc. indicators that will disrupt the interpretation process of individuals; it may be suggested to consider the fact that these individuals may have traumatic consequences during their visit. (4) The Maltese knights in Malta Mdina are purified from the propaganda content of the Local History Museum; It may be suggested to reconsider its presentation, paying attention to scientific and ethical values. Suggestions for Advanced Research: (1) In another study, it can be suggested to investigate the effect of three-dimensional figures made of wax and visual and auditory presentations on Turkish visitors, which are exhibited in the Local History Museum of the Knights of Malta and describe the historical process of Malta. (2) In another study, it may be suggested to investigate the effect of three-dimensional figures made of wax and visual and audio presentations on Turkish children visitors, which are exhibited in the Local History Museum of the Knights of Malta and that describe the historical process of Malta. (3) In another study, it may be suggested to investigate the effect of three-dimensional figures made of beeswax and visual and auditory presentations on visitors with special needs, which are exhibited in the Local History Museum of the Knights of Malta and describing the historical process of Malta. 